\title{
Comparison of Conventional DC-DC Converter and a Family of Diode-Assisted DC-DC Converter in Renewable Energy Applications
}

\author{
Yan Zhang ${ }^{*}$, Jinjun Liu ${ }^{\dagger}$, Xiaolong Ma*, and Junjie Feng ${ }^{*}$ \\ ${ }^{* *}$ State Key Laboratory of Electrical Insulation and Power Equipment, School of Electrical Engineering, Xi'an Jiaotong \\ University, Xi'an, China
}

\begin{abstract}
In the conventional dc-de converter, a pair of additional diode and the adjacent passive component capacitor/inductor can be added to the circuit with an X-shape connection, which generates a family of new topologies. The novel circuits, also called diode-assisted dc-dc converter, enhance the voltage boost/buck capability and have a great potential for high step-up/step-down power conversions. This paper mainly investigates and compares conventional dc-dc converter and diode-assisted dc-dc converter in wide range power conversion from the aspects of silicon devices, passive components requirements, electro-magnetic interference (EMI) and efficiency. Then, a comprehensive comparison example of a high step-up power conversion system was carried out. The two kinds of boost dc-dc converters operate under the same operation conditions. Mathematical analysis and experiment results verify that diode-assisted dc-dc converters are very promising for simultaneous high efficiency and high step-up/step-down power conversion in distributed power supply systems.
\end{abstract}

Key words: DC-DC converter, Diode-assisted converter, High step-down, High step-up

\section{INTRODUCTION}

Renewable energy sources such as photovoltaic (PV) arrays and fuel cells have been increasing at a fast pace and demonstrate great potential in advanced distributed power supply systems. The obvious characteristic of these primary sources is low dc voltage supply with wide range voltage drop [1]-[3]. With regard to this property, numerous applications including PV generation systems, fuel cells back-up uninterruptible power supply system (UPS) and electric vehicles, have to employ a high step-up/step-down dc-dc converter to integrate the renewable energy source with the utility equipment [4]-[26]. In addition, considering that the overall cost of renewable energy systems is high, the use of low cost, high efficiency power electronic converters is necessary.

The previously mentioned applications require high step-up/step-down power conversions. The conventional

Manuscript received Apr. 17, 2013; accepted Oct. 31, 2013

Recommended for publication by Associate Editor Honnyong Cha.

${ }^{\dagger}$ Corresponding Author: jjliu@mail.xjtu.edu.cn

Tel: +86-137-5996-1586, Fax: +86-8266-5223, Xi' an Jiaotong University

*State Kay Laboratory of Electrical Insulation and Power Equipment,

School of Electrical Engineering, Xi'an Jiaotong University, China dc-dc converter can theoretically boost/buck the output voltage to any desired value without the upper/lower limitation. However, in practical cases, the duty ratio cannot tends to be the extreme value unity/zero due to the parasitic parameters of the main circuit and the maximum/minimum adjustable on-time interval of the pulse-width modulation (PWM) controllers [5], [8]. Furthermore, the high-frequency EMI issue and efficiency are unfavorable since the switching devices suffer from high voltage and current stress when the conventional dc-dc converter operates under the extreme duty ratio [12], [13]. Typical solutions include the use of high-frequency power transformers to adjust the voltage gain. Unfortunately, this may result in an increased size and weight when compared with non-isolated dc-dc converters. Cascading one or more conventional dc-dc converters may be applied to obtain high step-up/step-down power conversions. Even though an additional power processing stage exists, the operation in the continuous conduction mode (CCM) may still lead to high efficiency [5]. The main drawbacks in this case are increased complexity and the need for two sets of active switches, magnetic cores and control circuits. In addition, the control must be synchronized and stability is a matter of great concern [5]. 


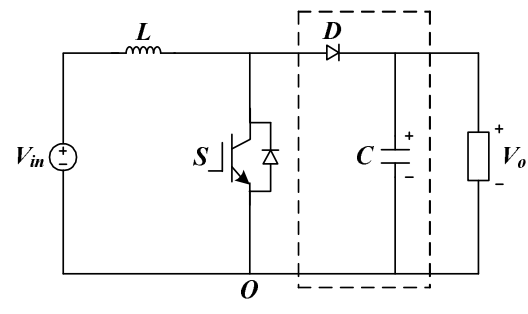

(a) Conventional boost converter.

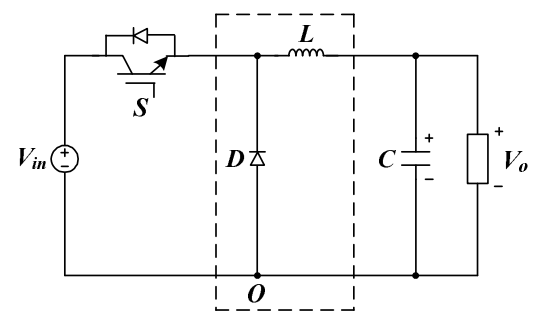

(c) Conventional buck converter.

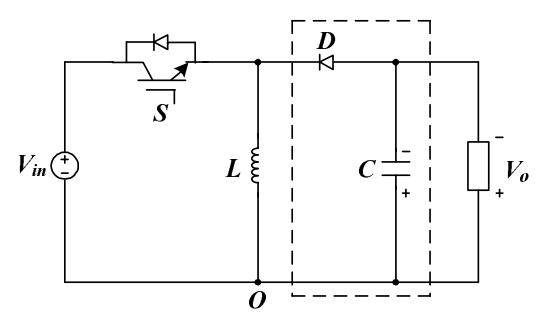

(e) Conventional buck-boost converter.

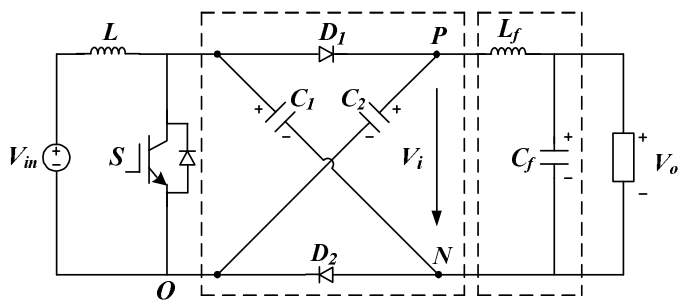

(b) Diode-assisted boost converter.

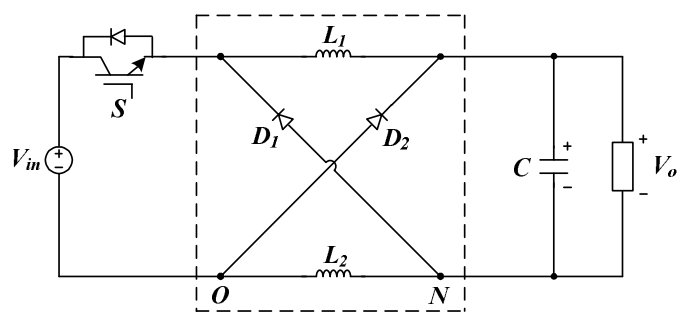

(d) Diode-assisted buck converter.

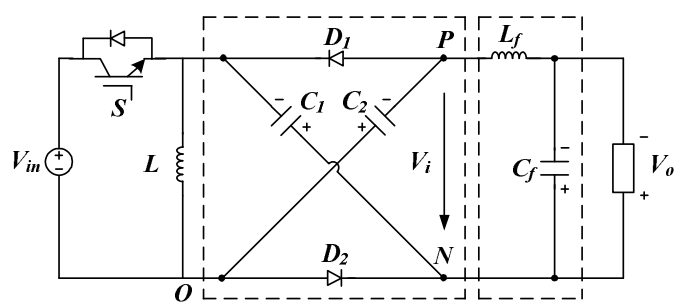

(f) Diode-assisted buck-boost converter.

Fig. 1. Conventional dc-dc converters and diode-assisted dc-dc converters.

Switched-capacitor/inductor network provides another solution to achieve high step-up/step-down power conversions [11]-[13]. The capacitor/inductor can be taken as an additional voltage/current source, which is switched and recombined by the power devices. Based upon the above principles, another pair of diode and the adjacent passive component capacitor/inductor is added into the conventional dc-dc circuit with an X-shape connection, which generates a family of novel topologies. The new circuits, also named diode-assisted dc-dc converters [21]-[23], enhance the voltage boost/buck capability and avoid the extreme duty ratio. It is also beneficial to alleviate the reverse-recovery current issue of power diode. Furthermore, diode-assisted dc-dc converters, as the single stage converters, do not increase control complexity. Thus, they demonstrate great potential advantages for wide range power conversion in renewable energy applications.

In order to quantify the improvement of the new topologies, this paper provides the mathematical analysis and makes fair comparisons of conventional dc-dc converters and diodeassisted dc-dc converters in terms of voltage gain, power rating of the total switching devices, passive component requirements, EMI and efficiency. The advantages and suitable operating conditions of each dc-dc converter in practical applications are discussed in detail.

\section{DC-DC CONVERTER TOPOLOGIES}

As previously mentioned, three sets of conventional dc-dc converters and diode-assisted dc-dc converters have been investigated [10]-[13]. The corresponding topologies of the main circuits are shown in Fig. 1 (a)-(f): conventional boost converter and diode-assisted boost converter; conventional buck converter and diode-assisted buck converter; conventional buck-boost converter and diode-assisted buck-boost converter. The new circuits introduce another pair of diode and capacitor/inductor based on the conventional dc-dc circuits. It is assumed that the capacitors/inductors in diode-assisted network have the same capacitance/inductance respectively due to the symmetrical $\mathrm{X}$-shape connection. Furthermore, an $L C$ filter is available at the output side to attenuate voltage ripples. Since only one controlled switching device exists in these circuits, each of diode-assisted dc-dc converters has two operation modes according to the switching state of $S$.

As for diode-assisted boost dc-dc converter, two diodes are reverse biased when $S$ is turned on. During this interval, the inductor $(L)$ absorbs energy from the dc source by increasing 


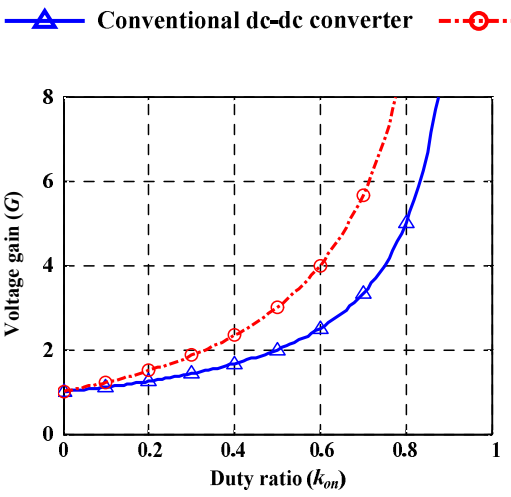

(a) Boost converters.

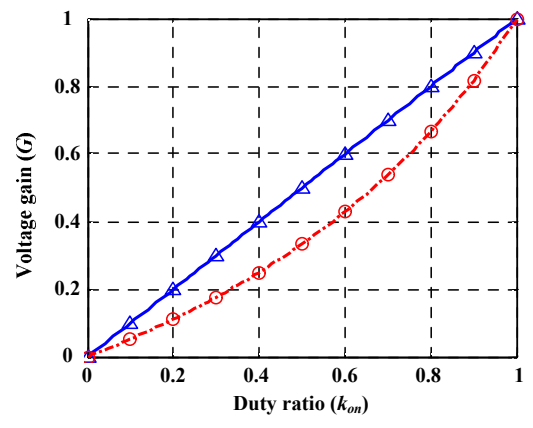

(b) Buck converters.

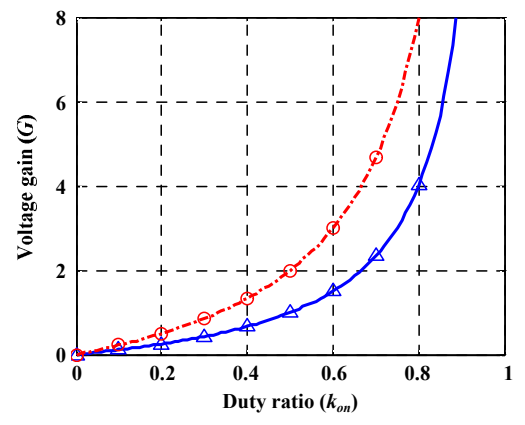

(c) Buck-boost. converters.

Fig. 2. Voltage gain versus duty ratio for conventional dc-dc converter and diode-assisted dc-dc converter.

the charging current, and two identical capacitors $\left(C_{1}\right.$ and $\left.C_{2}\right)$ are connected in series to supply the output terminal $\left(V_{i}=2 V_{C}\right)$. When $S$ is turned off, two diodes are forward biased. The energy accumulated in $L$ is transferred to $C_{I}$ and $C_{2}$. Both of the capacitors are connected in parallel to supply the output terminal $\left(V_{i}=2 V_{C}\right)$. With regard to the chopped intermediate dc link voltage $\left(V_{i}\right)$, an additional $L C$ filter is introduced at the output side to obtain a relatively constant output voltage. Since $D_{1}$ and $D_{2}$ are naturally conducting to perform parallel capacitive charging and are reverse-biased in the next interval to realize series capacitive discharging, a relatively high voltage can be easily achieved with the suitable boost duty ratio. The average voltage across the inductors $L_{l}$ and $L_{f}$ over one switching time period should be zero in the steady state.

$$
\begin{gathered}
V_{L 1}=\frac{k_{o n} T_{s} V_{i n}+k_{o f f} T_{s}\left(V_{i n}-V_{C}\right)}{T_{s}}=0 \\
V_{L_{f}}=\frac{k_{o n} T_{s}\left(2 V_{C}-V_{C_{f}}\right)+k_{o f f} T_{s}\left(V_{C}-V_{C_{f}}\right)}{T_{s}}=0
\end{gathered}
$$

From (1) and (2), the voltage gain of diode-assisted boost dc-dc converter can be expressed as [11]:

$$
G_{D_{-} \text {boost }}=\frac{V_{o}}{V_{\text {in }}}=\frac{1+k_{o n}}{1-k_{\text {on }}} .
$$

Evidently, $G_{D_{-} \text {boost }}$ is larger than that of conventional boost dc-dc circuit under the same boost duty ratio $\left(k_{o n}\right)$.

Diode-assisted buck converter employs an X-shape diode-inductor network between $S$ and the output capacitor. When $S$ is turned on, both inductors $\left(L_{1}\right.$ and $\left.L_{2}\right)$ and the output capacitor $(C)$ store energy in series. When $S$ is turned off, the two diodes are conducting. During this interval, $L_{l}$ and $L_{2}$ are connected in parallel to charge $C$. Using the aforementioned derivation approach, the average voltage across each inductor in the steady state meets:

$$
V_{L 1}=V_{L 2}=\frac{k_{\text {on }} T_{s} \frac{\left(V_{\text {in }}-V_{C}\right)}{2}+k_{\text {off }} T_{s}\left(-V_{C}\right)}{T_{s}}=0
$$

Solving (4), the voltage gain of this topology is:

$$
G_{D_{-} \text {buck }}=\frac{V_{C}}{V_{\text {in }}}=\frac{k_{\text {on }}}{2-k_{\text {on }}} .
$$

Evidently, the voltage gain is much smaller than that of conventional buck dc-dc circuit under the same duty ratio.

Diode-assisted buck-boost converter introduces the diode-capacitor network, which is the same as that of diode-assisted boost converter. When $S$ is turned on, $L$ absorbs energy from the dc source. Both capacitors $\left(C_{I}\right.$ and $C_{2}$ ) and the dc source are reversely connected to supply the output terminal. When $S$ is turned off, the energy stored in $L$ is transferred to $C_{1}, C_{2}$ and both of the capacitors are connected in parallel to supply the output terminal. With a similar derivation approach, the voltage across the inductors $L$ and $L_{f}$ in the steady state meets:

$$
\begin{gathered}
V_{L}=\frac{k_{o n} T_{s} V_{i n}+k_{o f f} T_{s}\left(-V_{C}\right)}{T_{s}}=0 \\
V_{L_{f}}=\frac{k_{o n} T_{s}\left(V_{i n}+2 V_{C}-V_{C_{f}}\right)+k_{o f f} T_{s}\left(V_{C}-V_{C_{f}}\right)}{T_{s}}=0
\end{gathered}
$$

Solving (6) and (7), the voltage gain of this topology is:

$$
G_{D_{-} \text {buck-boost }}=\frac{V_{o}}{V_{\text {in }}}=\frac{2 k_{\text {on }}}{1-k_{\text {on }}} .
$$

Evidently, the voltage gain is larger than that of the conventional buck-boost converter under the same duty ratio.

Fig. 2 shows the relationship of voltage gain versus the duty ratio for conventional $\mathrm{dc}-\mathrm{dc}$ converters and diode-assisted dc-dc converters. Based on the conventional dc-dc circuits, diode-assisted dc-dc circuits introduce a slight modification to enhance the voltage regulation capability without increasing the control complexity. Furthermore, the new topologies avoid the extreme duty ratio in high step-up/step-down voltage regulations. 
TABLE I

Voltage Gain and Switching Device ReQuirements for Different Converters

\begin{tabular}{|c|c|c|c|c|c|c|}
\hline \multirow[b]{2}{*}{ Converter } & \multicolumn{2}{|c|}{ Boost power conversion } & \multicolumn{2}{|c|}{ Buck power conversion } & \multicolumn{2}{|c|}{ Buck-Boost power conversion } \\
\hline & $\begin{array}{c}\begin{array}{c}\text { Conventional } \\
\text { converter }\end{array} \\
\end{array}$ & $\begin{array}{c}\begin{array}{c}\text { Diode-assisted } \\
\text { converter }\end{array} \\
\end{array}$ & $\begin{array}{c}\begin{array}{c}\text { Conventional } \\
\text { converter }\end{array} \\
\end{array}$ & $\begin{array}{c}\text { Diode-assisted } \\
\text { converter }\end{array}$ & $\begin{array}{c}\begin{array}{c}\text { Conventional } \\
\text { converter }\end{array} \\
\end{array}$ & $\begin{array}{c}\text { Diode-assisted } \\
\text { converter }\end{array}$ \\
\hline $\begin{array}{l}\text { Voltage gain } \\
\left(G=V_{o} / V_{i n}\right)\end{array}$ & $\frac{1}{1-k_{o n}}$ & $\frac{1+k_{o n}}{1-k_{o n}}$ & $k_{\text {on }}$ & $\frac{k_{o n}}{2-k_{o n}}$ & $\frac{k_{o n}}{1-k_{o n}}$ & $\frac{2 k_{o n}}{1-k_{o n}}$ \\
\hline $\begin{array}{l}\text { Voltage stress of switch } \\
\left(V_{S_{-} S} / V_{i n}\right)\end{array}$ & $G$ & $\frac{G+1}{2}$ & 1 & $1+G$ & $G+1$ & $\frac{G+2}{2}$ \\
\hline $\begin{array}{l}\text { Voltage stress of diode } \\
\left(V_{S_{-} D} / V_{\text {in }}\right)\end{array}$ & $G$ & $\frac{G+1}{2}$ & 1 & $\frac{G+1}{2}$ & $G+1$ & $\frac{G+2}{2}$ \\
\hline $\begin{array}{l}\text { Current stress of switch } \\
\qquad\left(I_{S_{-} S} / I_{i n}\right)\end{array}$ & $\frac{G-1}{G}$ & $\frac{G-1}{G}$ & 1 & 1 & 1 & 1 \\
\hline $\begin{array}{l}\text { Current stress of diode } \\
\qquad\left(I_{S_{-} D} / I_{\text {in }}\right)\end{array}$ & $\frac{1}{G}$ & $\frac{1}{G}$ & $\frac{1-G}{G}$ & $\frac{1-G}{2 G}$ & $\frac{1}{G}$ & $\frac{1}{G}$ \\
\hline $\begin{array}{c}\text { Silicon devices power } \\
\text { Rating }\left((S D P)_{\text {Sum }} / P_{i n}\right)\end{array}$ & $G$ & $\frac{(G+1)^{2}}{2 G}$ & $\frac{1}{G}$ & $\frac{(G+1)^{2}}{2 G}$ & $\frac{(G+1)^{2}}{G}$ & $\frac{(G+2)^{2}}{2 G}$ \\
\hline
\end{tabular}

$I_{\text {in }}$ denotes the average input current; $P_{\text {in }}$ denotes the input power.

\section{COMPARISON ITEMS, EQUATIONS AND RESULTS}

Efficiency and cost are important criteria for designing a power converter in renewable energy applications. In order to make a comparison of conventional dc-dc circuits and diode-assisted dc-dc circuits with no partiality, two related converters with the identical function are assumed to operate under the same conditions: input dc source voltage $\left(V_{i n}\right)$, voltage gain $(G)$, output power $\left(P_{o}\right)$ and switching time $\operatorname{period}\left(T_{s}\right)$.

\section{A. Requirement Comparison of Switching Devices}

The key parameters for the selection of each of the silicon power devices in dc-dc converter are the voltage stress $\left(V_{S}\right)$ : the maximum blocking voltage across the device when it is turned off and the average current stress $\left(I_{S}\right)$ : the average current flowing through the device in one switching time period. As described in [24]-[26], the switching device power rating $(S D P)$ as the product of the voltage stress $\left(V_{S}\right)$ and average current stress $\left(I_{S}\right)$ is introduced as a cost indicator for the power device. The switching device power rating of all the semiconductor devices used in the circuit can be a rough cost estimation of the converter system. Furthermore, it is also an indicator of the thermal requirements and conversion efficiency.

$$
(S D P)_{S u m}=\sum_{i=1}^{N} V_{S i} \cdot I_{S i}
$$

where $N$ is the number of power devices used, $V_{S i}$ is the voltage stress induced on the device, and $I_{S i}$ is the average current through the device.

According to the aforementioned operation principle, the expressions of the voltage stress, current stress and total power rating of the switching devices can be obtained and listed in Table I. The detailed derivation process for the boost converter as a reference is in Appendix I.

For direct viewing, Fig. 3 shows the switching device comparison results between conventional dc-dc converters and diode-assisted dc-dc converters. As illustrated in Fig. 3 (a), the voltage stress across the switching device in diode-assisted boost converter is much smaller than that in conventional boost converter. In addition, the gap expands quickly with an increase in the voltage gain. In the meantime, the switching devices including $S$ and the diodes in the two converters can withstand the same current stress under the given voltage gain, respectively. As a result, diode-assisted boost converter retains the smaller $(S D P)_{S U M}$, especially in high voltage gain applications.

Fig. 3 (b) shows the comparison results of the two kinds of buck converters. The voltage stress of $S$ in diode-assisted buck converter is a little larger than that in conventional buck converter. However, the difference is reduced with a decrease in the voltage gain. The voltage stress of each diode in diode-assisted buck converter is smaller than that in conventional buck converter. As for the current stress, $S$ in both converters suffer by the same value. In addition, the current stress of each diode in diode-assisted buck converter retains the smaller value. Therefore, diode-assisted buck converter exhibits the relatively smaller $(S D P)_{S U M}$, especially under low voltage gain applications.

Fig. 3 (c) shows the comparison results of the two kinds of buck-boost converters. This case is very similar to the comparison results of the boost converters. The voltage stress of each of the switching devices in diode-assisted buck-boost 

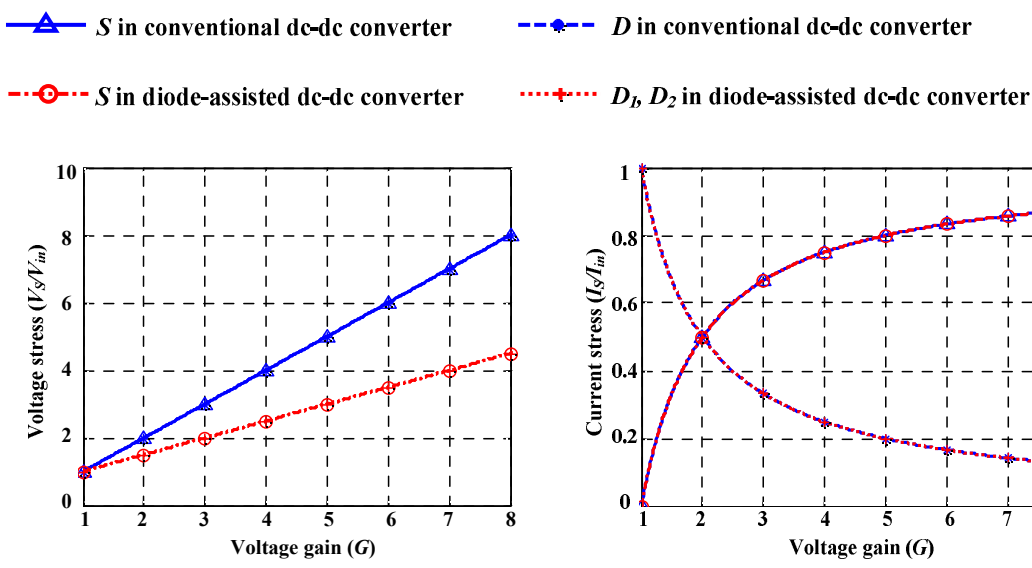

(a) Switching device comparison between conventional boost converter and diode-assisted boost converter.
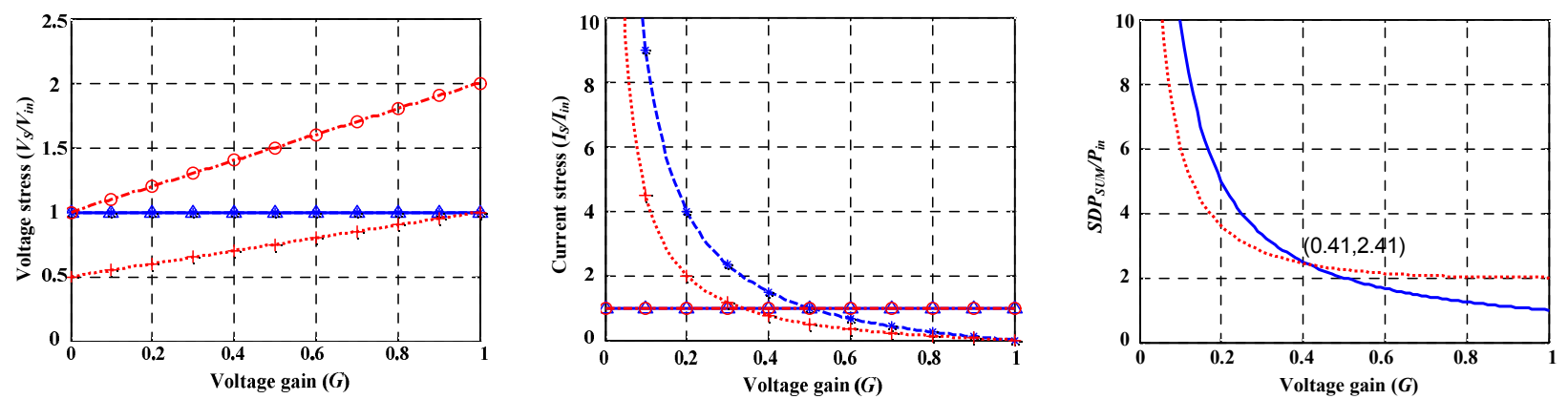

(b) Switching device comparison between conventional buck converter and diode-assisted buck converter.
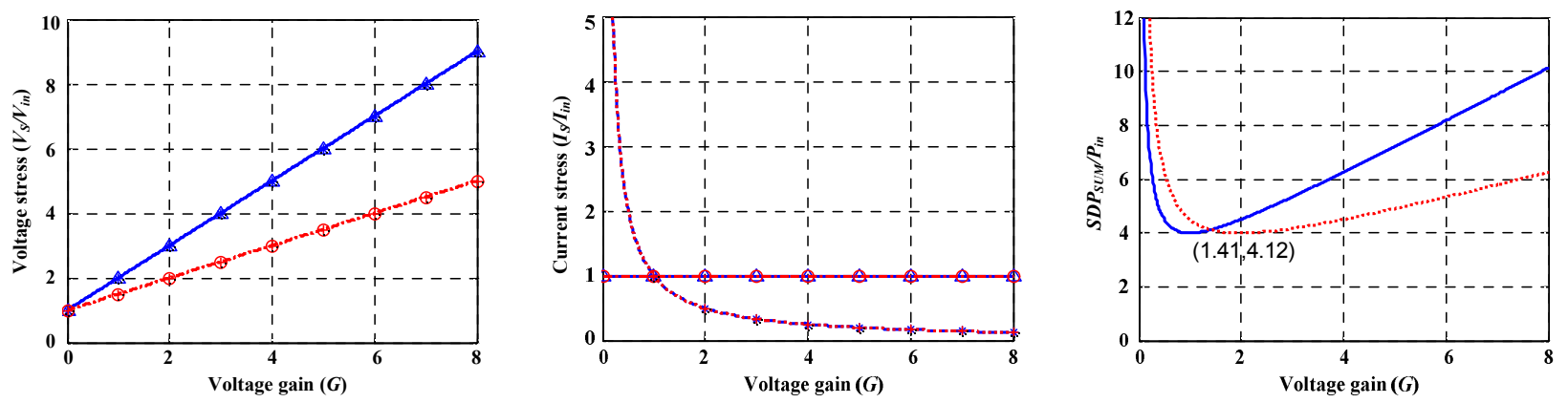

(c) Switching device comparison between conventional buck-boost converter and diode-assisted buck-boost converter.

Fig. 3. Switching device comparison between conventional dc-dc converters and diode-assisted dc-dc converters

converter are much smaller than that in conventional converter, while the current stress of the corresponding devices in both converters has the same value. As a result, diode-assisted buck-boost converter retains the smaller $(S D P)_{S U M}$, especially in high voltage gain applications.

\section{B. Requirements Comparison of Passive Components}

The passive components including the inductor and capacitor are also important parts in determining the cost and volume of power converters. In general, the volume of a passive component is proportional to the available energy stored in it. The inductor core and winding are designed on the basis of the inductance requirement $(L)$ and average current level $\left(I_{L}\right)$ under normal operation conditions. The inductance is selected by limiting the current ripple to a certain range. If the current ripple or the current level is small, the volume of the inductor can be reduced. The capacitor is designed based on the current capacity, capacitance requirement and terminal voltage [27]. The current capacity usually refers to the root mean square $(R M S)$ value of the current ripple. The capacitance is selected according to the limitations of the voltage ripple. According to the operation principles of the different converters, the key parameters for inductor and capacitor selection in each circuit are obtained and listed in Table II. The detailed derivation process for boost converters as a reference is provided in Appendix II. 
TABLE II

REQUiREMENTS OF PASSIVE COMPONENTS FOR DIFFERENT DC-DC CONVERTERS

\begin{tabular}{|c|c|c|c|c|c|c|}
\hline \multirow[b]{2}{*}{ Converter } & \multicolumn{2}{|c|}{ Boost power conversion } & \multicolumn{2}{|c|}{ Buck power conversion } & \multicolumn{2}{|c|}{ Buck-boost power conversion } \\
\hline & $\begin{array}{c}\text { Conventional } \\
\text { circuit }\end{array}$ & $\begin{array}{l}\text { Diode-assisted } \\
\text { circuit }\end{array}$ & $\begin{array}{l}\text { Conventional } \\
\text { circuit }\end{array}$ & $\begin{array}{l}\text { Diode-assisted } \\
\text { circuit }\end{array}$ & $\begin{array}{c}\text { Conventional } \\
\text { circuit }\end{array}$ & $\begin{array}{l}\text { Diode-assisted } \\
\text { circuit }\end{array}$ \\
\hline $\begin{array}{l}\text { Inductor current } \\
\text { ripple }\end{array}$ & $\Delta I_{L}=\frac{G-1}{G} \frac{V_{i}}{L \cdot f_{s}}$ & $\begin{aligned} \Delta I_{L} & =\frac{G-1}{G+1} \frac{V_{i}}{L \cdot f_{s}} \\
\Delta I_{L_{f}} & =\frac{G-1}{G+1} \frac{V_{i}}{L \cdot f_{s}}\end{aligned}$ & $\Delta I_{L}=G(1-G) \frac{V_{i}}{L \cdot f_{s}}$ & $\Delta I_{L}=\frac{G(1-G)}{1+G} \frac{V_{i n}}{L \cdot f_{s}}$ & $\Delta I_{L}=\frac{G}{G+1} \frac{V_{\text {in }}}{L \cdot f_{s}}$ & $\begin{aligned} \Delta I_{L} & =\frac{G}{G+2} \frac{V_{i n}}{L \cdot f_{s}} \\
\Delta I_{L_{f}} & =\frac{G}{G+2} \frac{V_{i n}}{L_{f} \cdot f_{s}}\end{aligned}$ \\
\hline $\begin{array}{c}\text { Inductor average } \\
\text { current }\end{array}$ & $I_{L}=I_{i n}$ & $\begin{array}{c}I_{L_{1}}=I_{i n} \\
I_{L_{f}}=\frac{1}{G} I_{i n}\end{array}$ & $I_{L}=\frac{1}{G} I_{i n}$ & $I_{L}=\frac{1+G}{2 G} I_{i n}$ & $I_{L}=\frac{1+G}{G} I_{i n}$ & $\begin{array}{c}I_{L}=\frac{1+G}{G} I_{i n} \\
I_{L_{f}}=\frac{1}{G} I_{i n}\end{array}$ \\
\hline $\begin{array}{l}\text { Capacitor Voltage } \\
\text { ripple }\end{array}$ & $\Delta V_{C}=\frac{G-1}{G^{2}} \frac{I_{i n}}{C \cdot f_{s}}$ & $\begin{array}{c}\Delta V_{C_{1}}=\frac{G-1}{G(G+1)} \frac{I_{\text {in }}}{C_{1} \cdot f_{s}} \\
\Delta V_{C_{f}}=\frac{\Delta I_{L_{f}}}{8 C_{f} f_{s}}\end{array}$ & $\Delta V_{C}=\frac{\Delta I_{L}}{8 C f_{s}}$ & $\Delta V_{C}=\frac{1-G}{1+G} \frac{I_{i n}}{C \cdot f_{s}}$ & $\Delta V_{C}=\frac{1}{1+G} \frac{I_{\text {in }}}{C \cdot f_{s}}$ & $\begin{array}{c}\Delta V_{C_{1}}=\frac{1}{G+2} \frac{I_{i n}}{C_{1} \cdot f_{s}} \\
\Delta V_{C_{f}}=\frac{\Delta I_{L_{f}}}{8 C f_{s}}\end{array}$ \\
\hline $\begin{array}{l}\text { Capacitor current } \\
\text { ripple }\left(I_{C_{-} \text {rms }}^{2}\right)\end{array}$ & $I_{C_{-} r m s}^{2}=\frac{G-1}{G^{2}} I_{i n}^{2}$ & $\begin{array}{c}I_{C_{1}-r m s}^{2}=\frac{G-1}{2 G^{2}} I_{i n}^{2} \\
I_{C_{f-r m s}}^{2}=\frac{\Delta I_{L_{f}}^{2}}{12}\end{array}$ & $I_{C_{-} r m s}^{2}=\frac{\Delta I_{L}^{2}}{12}$ & $I_{C_{-} r m s}^{2}=\frac{1-G}{2 G} I_{i n}^{2}$ & $I_{C_{-} r m s}^{2}=\frac{1}{G} I_{i n}^{2}$ & $\begin{array}{l}I_{C_{1_{1} r m s}}^{2}=\frac{1}{2 G} I_{i n}^{2} \\
I_{C_{f-r m s}}^{2}=\frac{\Delta I_{L_{f}}^{2}}{12}\end{array}$ \\
\hline $\begin{array}{c}\text { Capacitor terminal } \\
\text { voltage }\end{array}$ & $V_{C}=G V_{i n}$ & $\begin{array}{c}V_{C_{1}}=\frac{G+1}{2} V_{i n} \\
V_{C_{f}}=G V_{i n}\end{array}$ & $V_{C}=G V_{i n}$ & $V_{C}=G V_{i n}$ & $V_{C}=G V_{i n}$ & $\begin{array}{l}V_{C_{1}}=\frac{G}{2} V_{i n} \\
V_{C_{f}}=G V_{i n}\end{array}$ \\
\hline
\end{tabular}

The current/voltage ripples of the passive components inductor/capacitor are defined as:

$$
\begin{aligned}
\Delta I_{L} & =\delta_{L} \cdot I_{L} \\
\Delta V_{C} & =\delta_{C} \cdot V_{C}
\end{aligned}
$$

where $\delta_{L}$ and $\delta_{C}$ are the ripple coefficients, which are preset based on the performance indices of the converter.

Based on the equations listed in Table II and the aforementioned definitions, the relationship of passive components requirements versus the voltage gain for the different kinds of dc-dc converters are shown in Fig. 4. The parameters $K_{L}, K_{C}$, and $K_{I c}$ are defined as:

$$
\begin{aligned}
K_{L} & =\frac{L}{V_{\text {in }} / \delta_{L} f_{s} I_{\text {in }}} \\
K_{C} & =\frac{C}{I_{\text {in }} / \delta_{C} f_{s} V_{i n}} \\
K_{I_{C}} & =\frac{I_{C_{-} r m s}^{2}}{I_{\text {in }}^{2}}
\end{aligned}
$$

where $K_{L}$ reflects the inductance requirement; and $K_{C}$ and $K_{I c}$ reflect the capacitance requirement and current ripple of capacitor.

As is illustrated in Fig. 4.(a), the inductance of the boost inductor for diode-assisted boost converter is reduced under the same input current ripple, when compared with conventional boost converter. The capacitance of diode-assisted boost converter is a little larger under high voltage gain applications. However, the $R M S$ current ripple and the terminal voltage of each capacitor $\left(C_{1}\right.$ and $\left.C_{2}\right)$ are decreased to a large extent, which contributes to the volume reduction. Furthermore, diode-assisted boost converter employs an $L C$ filter at the output side. Fortunately, the volume of the additional $L C$ filter does not enlarge the size of power converter too much. When compared with the main storage components, the boost inductor $(L)$ and the intermediate capacitors $\left(C_{I}\right.$ and $\left.C_{2}\right)$, the volume of the $L C$ filter is relatively minor because of the small values of $I_{L f}$ and $C_{f}$. Therefore, the total volume of the passive components may be reduced in high voltage gain applications, even though diode-assisted boost converter increases the number of passive components.

As for the passive components requirement comparison for the two kinds of buck dc-dc circuits shown in Fig. 4.(b), the inductance of each inductor $\left(L_{1}, L_{2}\right)$ in diode-assisted buck converter is a little larger than that in conventional buck converter under the same current ripple limitations. However, the average current level $\left(I_{L}\right)$ in the new circuit is much smaller. The volume of the inductor is proportional to the inductance and the square of the current level $\left(L \cdot I_{L}^{2}\right)$. As a result, diode-assisted buck converter also has potential in the volume reduction of inductors. In the conventional buck circuit, the output current is continuous and almost constant. However, in diode-assisted buck circuit, the charging current across the capacitor changes between once and twice the inductor current in one switching time period. Therefore, the capacitance and volume of the output capacitor in conventional buck converter are relatively small. 


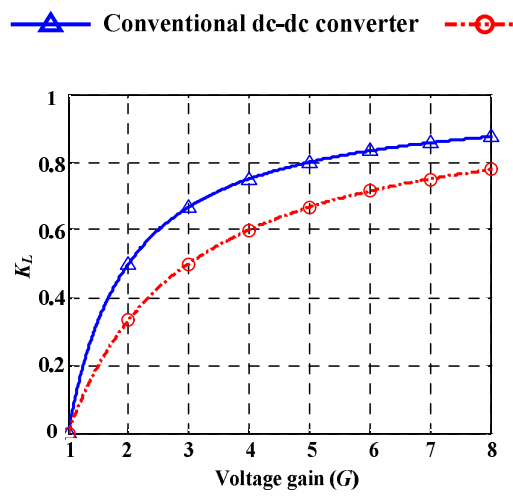

\section{Diode-assisted dc-dc converter}

(a) Inductance, capacitor voltage ripple and current ripple comparison between two kinds of boost converters.
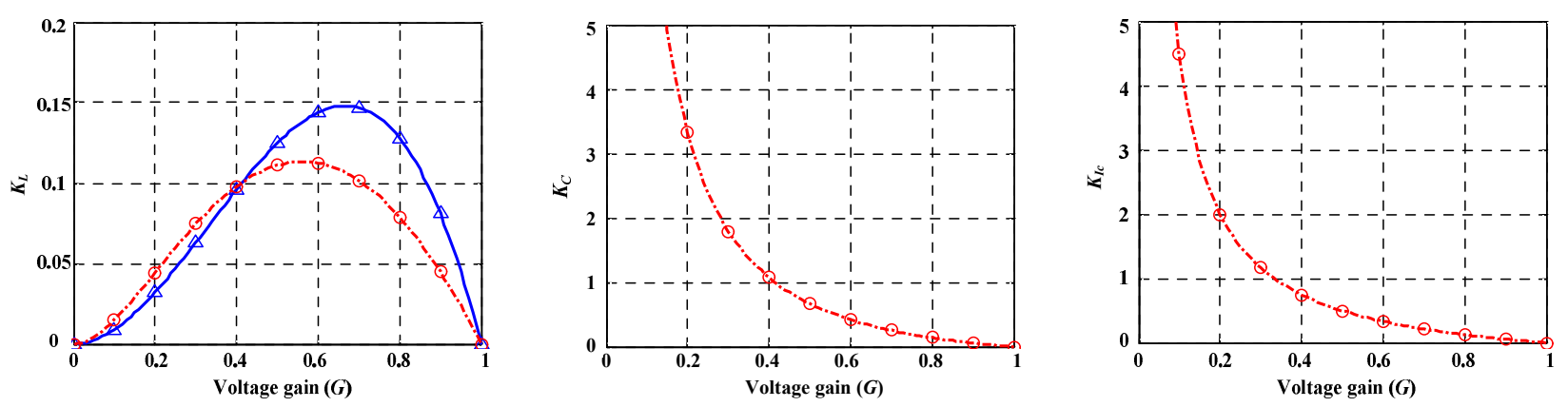

(b) Inductance, capacitor voltage ripple and current ripple comparison between two kinds of buck converters.
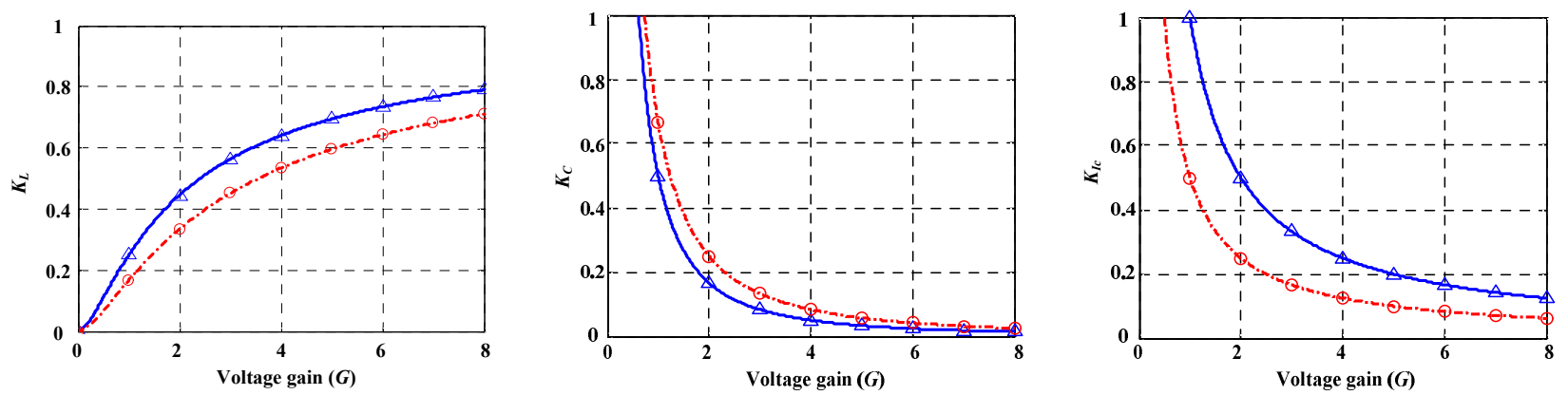

(c) Inductance, capacitor voltage ripple and current ripple comparison between two kinds of buck-boost converters.

Fig. 4. Passive components comparison between conventional dc-dc converters and diode-assisted dc-dc converters.

As for the two buck-boost circuits, the comparison results of the passive components are fairly similar to those of the boost circuits in high voltage gain applications. The inductance of $L$ in diode-assisted buck-boost converter can be reduced under the same current ripple, when compared with the conventional one. The capacitance of each capacitor in diode-assisted buck-boost converter is a little larger. However, the $R M S$ current ripple of each one is reduced to a large extent, which contributes to volume reduction.

\section{EMI Comparison}

In power electronic converters, EMI mainly refers to switching noise and common-mode noise. High values for the $d v / d t$ and $d i / d t$ during the switching instant are the major source of high frequency EMI. For conventional dc-dc converter operating under high step-up/step-down applications, the large voltage/current stress of switching devices will introduce the severe reverse recovery current of the power diode and serious high-frequency switching noise as the duty ratio $\left(k_{o n}\right)$ approaches the extreme value. From the switching device comparison, the enhanced dc-dc converters based on diode-capacitor/inductor network with decreased voltage/ current stress are beneficial for reducing the slope of $d v / d t$, $d i / d t$, which alleviates the reverse-recovery current problem of the power diode, as well as suppressing the high-frequency switching noise [12], [13].

As is illustrated in Fig. 1, there is no common ground between the input and output side for diode-assisted dc-dc 
TABLE III

COMPARISON EXAMPLE OF TwO BOOST CONVERTERS

\begin{tabular}{|c|c|c|c|c|c|c|c|c|}
\hline \multirow{2}{*}{$\begin{array}{c}\text { Boost } \\
\text { converter }\end{array}$} & \multicolumn{3}{|c|}{ Switching devices } & \multicolumn{4}{|c|}{ Passive components } & \multirow[b]{2}{*}{$\begin{array}{c}\text { Capacitor } \\
\text { voltage rating }\end{array}$} \\
\hline & $\begin{array}{r}\text { Vol } \\
\text { stres }\end{array}$ & & $(\mathbf{S D P})_{\text {sum }}$ & Ind & \begin{tabular}{|c|}
$\begin{array}{c}\text { Average inductor } \\
\text { current }(\mathrm{A})\end{array}$ \\
\end{tabular} & Capacitance & $\begin{array}{r}\text { Cap } \\
\text { ct }\end{array}$ & \\
\hline $\begin{array}{r}\text { Conv } \\
\text { cir }\end{array}$ & $\begin{array}{l}V_{S_{-} S}=540 \mathrm{~V} \\
V_{S_{-} D}=540 \mathrm{~V}\end{array}$ & $\begin{array}{l}I_{S_{-} S}= \\
I_{S_{-} D}=\end{array}$ & $9000 V A$ & $L=2.8 m H$ & $I_{L}=16.7 \mathrm{~A}$ & $C=2$ & $I_{C_{-} R M S}=6.9 \mathrm{~A}$ & $V_{C}=540 \mathrm{~V}$ \\
\hline $\begin{array}{c}\text { Diode-assisted } \\
\text { circuit }\end{array}$ & $\begin{array}{l}V_{S_{-} S}=330 \mathrm{~V} \\
V_{S_{-} D}=330 \mathrm{~V}\end{array}$ & $\begin{array}{l}I_{S_{-} S}=13 \mathrm{~A} \\
I_{S_{-} D}=3.7 \mathrm{~A}\end{array}$ & $6722 V A$ & $\begin{array}{c}L=2.3 \mathrm{mH} \\
L_{f}=6.9 \mathrm{mH}\end{array}$ & $\begin{array}{l}I_{L}=16.7 \mathrm{~A} \\
I_{L_{f}}=3.7 \mathrm{~A}\end{array}$ & $\begin{array}{l}C=357.1 u F \\
C_{f}=12.8 u F\end{array}$ & $\begin{array}{l}I_{C_{-} R M S}=4.9 \mathrm{~A} \\
I_{C_{f_{-} R M S}}=0.3 \mathrm{~A}\end{array}$ & $\begin{array}{l}V_{C}=330 \mathrm{~V} \\
V_{C_{f}}=540 \mathrm{~V}\end{array}$ \\
\hline
\end{tabular}

converters. Therefore, the common-mode voltage $\left(V_{O N}\right)$, as another important EMI source, is worth analysis in the novel circuits. As for diode-assisted boost converter, the maximum common-mode voltage takes place during $S=\mathrm{ON}$ interval according to the operation principle. And it is the intermediate capacitor voltage which can be expressed as:

$$
V_{O N\left(D_{-} \text {boost }\right)}=\frac{1}{1-k_{\text {on }}} V_{\text {in }}=\frac{G+1}{2} V_{\text {in }} .
$$

For diode-assisted buck converter, the inductor $L_{2}$ is connected between the input and output ground. Therefore, the corresponding maximum common-mode voltage is the absolute value of the charging and discharging voltage of $L_{2}$ during $S=\mathrm{ON}$ and $S=\mathrm{OFF}$ intervals.

$$
V_{O N\left(D_{-} \text {buck }\right)}=\max \left(\frac{1-G}{2} V_{i n}, G V_{i n}\right) \text {. }
$$

For diode-assisted buck-boost converter, the maximum common-mode voltage between the input and output ground takes place during $S=\mathrm{ON}$ interval. And it is the blocking voltage across $D_{2}$.

$$
V_{\text {ON(D_buckboost })}=\frac{1}{1-k_{\text {on }}} V_{\text {in }}=\frac{G+2}{2} V_{\text {in }} .
$$

Evidently, diode-assisted dc-dc converters have the potential to reduce the cost of silicon devices, the volume of passive components and the high-frequency switching noise, when compared with conventional dc-dc converters. However, the common-mode voltage does exist and needs necessary consideration in some applications. Anyway, diode-assisted $\mathrm{dc}-\mathrm{dc}$ converters are the promising topologies in high step-up/step-down power conversion.

\section{COMPARISON EXAMPLE AND EXPERIMENTAL VERIFICATION}

To verify the advantages of diode-assisted dc-dc circuits, a comparison example, taking the boost conversion system as a reference, will be conducted with the following parameters: $V_{\text {in }}=120 \mathrm{~V}, V_{o}=540 \mathrm{~V}, P_{o}=2 \mathrm{~kW}$ and $f_{s}=10 \mathrm{kHz}$. This application requires high step-up voltage regulation. According to the equations listed in Tables I and II. The key parameters for the switching devices and passive components selection can be calculated and shown in Table III. The current/voltage ripple

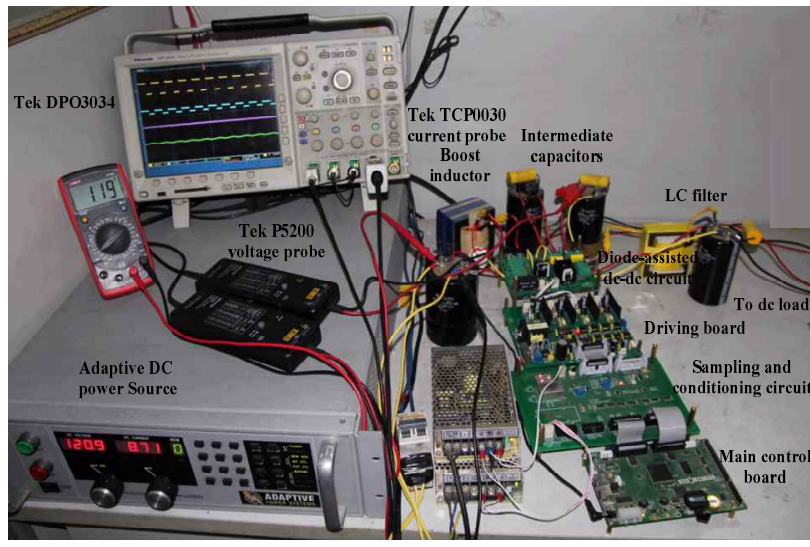

Fig. 5. Diode-assisted dc-dc converter test platform.

\section{TABLE IV}

The SPECIFICATIONS FOR THE EXPERIMENTAL PROTOTYPE

\begin{tabular}{|c|c|c|}
\hline \multirow{2}{*}{ Power devices } & $S$ & IGBT (IGW40T120) \\
\cline { 2 - 3 } & $D, D_{I}$ and $D_{2}$ & DIODE (IDP30E120) \\
\hline \multirow{2}{*}{ Passive components } & $L$ & $2.5 \mathrm{mH}$ \\
\cline { 2 - 3 } & $C, C_{1}$ and $C_{2}$ & $330 \mathrm{uF}$ \\
\hline \multirow{2}{*}{$L C$ filer } & $L_{f}$ & $7 \mathrm{mH}$ \\
\cline { 2 - 3 } & $C_{f}$ & $47 \mathrm{uF}$ \\
\hline Resistance load & $R$ & $40 \Omega \sim 1000 \Omega$ \\
\hline Switching time period & $T_{s}$ & $100 \mathrm{us}$ \\
\hline
\end{tabular}

coefficients of each inductor/capacitor for two boost converters are preset as: $\delta_{L}=0.2, \delta_{L f}=0.3, \delta_{C}=0.002$ and $\delta_{C f}=0.002$. Evidently, $(S D P)_{S U M}$ of diode-assisted boost circuit is much smaller than that of conventional circuit. Usually, $(S D P)_{S U M}$ is also a measurement of the thermal requirements. Therefore, a small value of $(S D P)_{S U M}$ contributes to reducing the cost of the switching devices and the size of the heatsink. As for passive component requirements listed in Table III, diode-assisted boost circuit reduces the inductance of the boost inductor $(L)$, the terminal voltage and the $R M S$ current of the intermediate capacitor $\left(C_{l}\right)$, which promotes volume minimization. Even though the new topology employs an $L C$ filter at the output side, the additional circuit may not increase the total volume of the converter greatly due to the relatively small output current across $L_{f}$, and the small capacitance and $R M S$ current of $C_{f}$. 


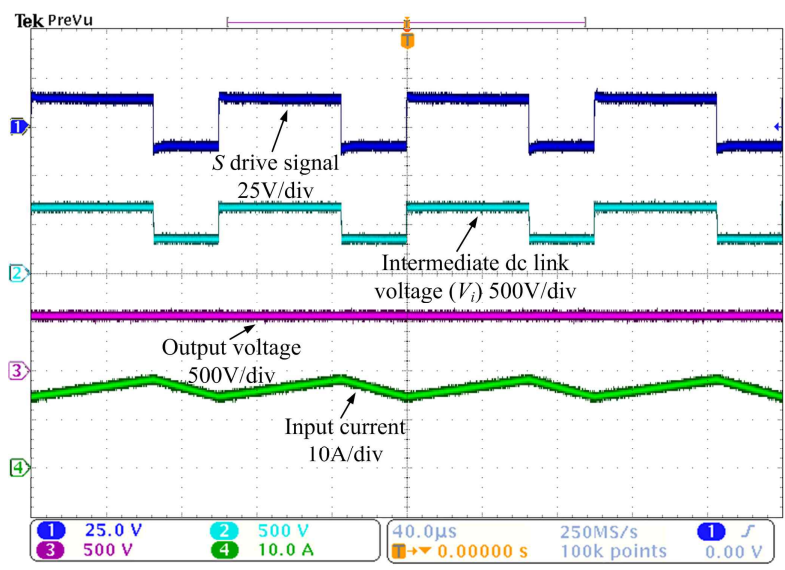

(a) Waveforms of drive signal, intermediate dc-link voltage, output voltage and input current.

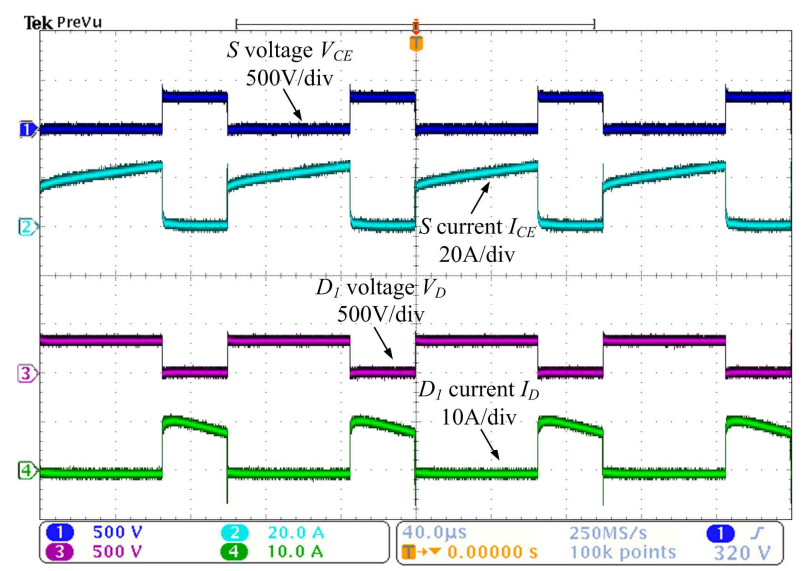

(b) Switching waveforms of power devices.

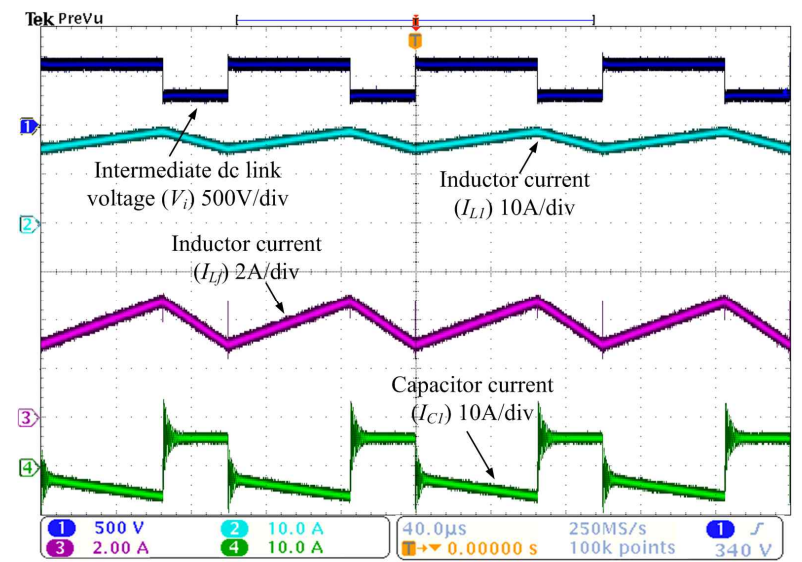

(c) Current waveforms of passive components.

Fig. 6. Experiment waveforms of diode-assisted boost converter.

A laboratory prototype rated at $2 \mathrm{~kW}$ was built to confirm the previous theoretical analysis with Infineon power devices. Conventional boost dc-dc converter is also set up as a counterpart for comparison. The main control board is designed based on DSP28335. Fig. 5 shows a photograph of the test platform.

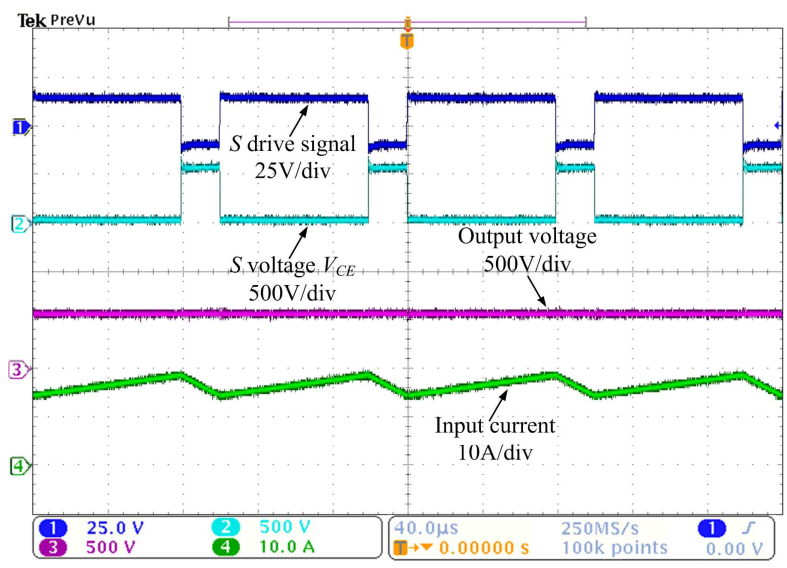

(a) Waveforms of drive signal, switching voltage, output voltage and input current.

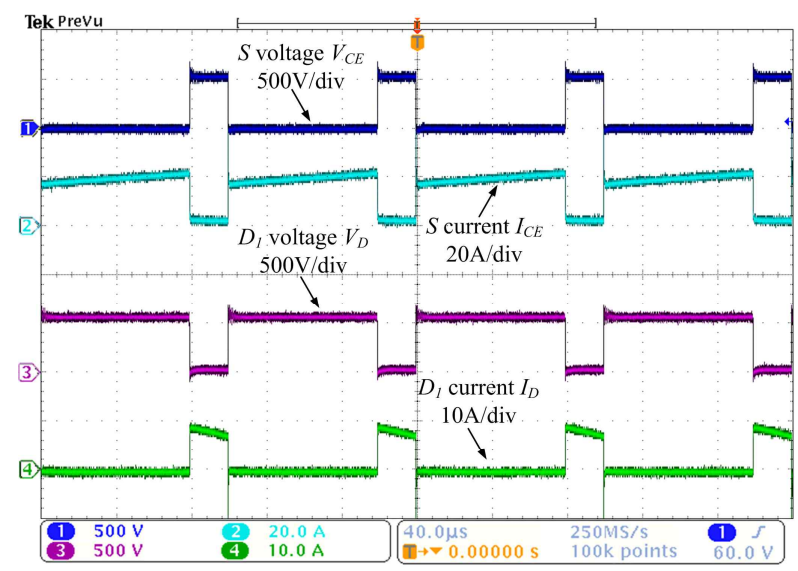

(b) Switching waveforms of power devices.

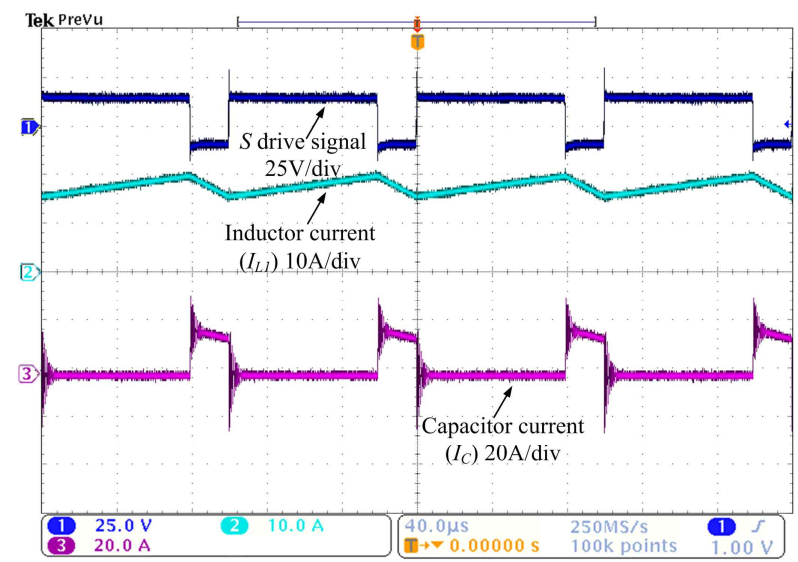

(c) Current waveforms of passive components.

Fig. 7. Experiment waveforms of conventional boost converter.

Figs. 6 and 7 show the measured experimental waveforms of diode-assisted boost converter and the conventional boost converter, respectively. Both converters operate under the preset conditions: $V_{\text {in }}=120 \mathrm{~V}, V_{o}=540 \mathrm{~V}, f_{s}=10 \mathrm{kHz}, R=150 \Omega$ and the voltage gain is about $G=4.5$. As is illustrated in Figs. 6(a) and 7(a), the duty ratio of $S$ in diode-assisted boost 
converter is reduced to a large extent under the same voltage gain. The current ripple also decreases at the same time. Under normal operation, all of the power devices in diode-assisted boost converter withstand the intermediate capacitor voltage, while all of the power devices in the conventional boost converter bear a high output voltage. The on-state current of the power devices in conventional boost converter is the boost inductor current. Meanwhile, the on-state current of $S$ in diode-assisted boost converter is the sum of the input and output current. As for the switching waveforms shown in Figs. 6(b) and 7(b), the measured blocking voltage and on-state current of the power devices are: $336 \mathrm{~V}, 20.5 \mathrm{~A}$ for diode-assisted boost converter and $538 \mathrm{~V}, 16.9 \mathrm{~A}$ for conventional boost converter. All of these measured value are almost consistent with the theoretical values of $330 \mathrm{~V}, 19.8 \mathrm{~A}$ and $540 \mathrm{~V}, 16.2 \mathrm{~A}$, respectively. Figs. 6(c) and 7(c) show the captured current waveforms of the passive components $\left(i_{L}, i_{C}, i_{C f}\right)$, which accord well with the aforementioned mathematical analysis results. The current ripple of $L$ in diode-assisted boost converter is a little smaller than that of conventional boost converter with the same boost inductance. The relatively obvious oscillatory current of the capacitor appears at the instant of the switching commutation and reflects the switching current across the power devices. Diode-assisted boost converter is beneficial for reducing the current ripple across the capacitors.

Efficiency is an important criterion for power converter. High efficiency can reduce both the thermal requirements and cost. The losses of power converter comprise the semiconductor devices losses, passive devices losses, controller and driver losses, etc. in which the semiconductor device losses are the dominant part. The semiconductor device losses mainly include switching loss and conduction loss. For the fully controllable IGBT, there are turn-on and turn-off switching losses in addition to the conduction loss, while for the power diode only the reverse recovery loss and conduction loss are considered because the turn-on loss of diode is small enough to be negligible. The switching loss model of semiconductor devices can be expressed as a function of the switched current and blocking voltage as [28]-[30]:

$$
\begin{aligned}
& E_{s w(o n, o f f)}=\left(\alpha+\beta \cdot i_{s w}+\gamma \cdot i_{s w}^{2}\right) \frac{V_{s w}}{V_{r e f}} \\
& P_{s w}=f_{s w} \cdot\left(E_{s w o n}+E_{s w o f f}\right)
\end{aligned}
$$

where $V_{s w}$ is the blocking voltage; $i_{s w}$ is the switched current; and $\alpha, \beta, \gamma$ are the device parameters from the manufacturer datasheet. $V_{\text {ref }}$ is the reference voltage under which the device parameters are derived.

The conduction losses for the power devices IGBT and DIODE in the dc-dc converter $\left(P_{c o n d c}\right)$ can be calculated as:

$$
P_{\text {con_dc }}=\frac{1}{T_{s}} \int_{0}^{T_{s}} v_{c o n}(t) \cdot i_{c o n}(t) d t \approx d_{c o n} \cdot v_{c o n}(t) \cdot i_{c o n}(t)
$$

where $v_{c o n}(t)=v_{\text {on }}+r i_{c o n}(t)$ is the on-state voltage drop; $v_{o n}$ is the threshold voltage; and $r$ is the on-state resistor. $i_{c o n}$ is the conduction current, and $d_{c o n}$ is the conduction duration.

As indicated in (15) and (16), the switching loss of power converter depends on the switching frequency $\left(f_{s w}\right)$, switched current $\left(i_{s w}\right)$ and blocking voltage $\left(V_{s w}\right)$. The key parameters for the conduction loss calculation of power device expressed in $(17)$ are the conduction duration $\left(d_{c o n}\right)$ and the on-state current $\left(i_{c o n}\right)$. For conventional dc-dc boost converter, the blocking voltage of the power devices is the high output voltage. The switched current $\left(i_{s w}\right)$ and on-state current $\left(i_{c o n}\right)$ of power devices are the large input current. Therefore, the efficiency of conventional boost converter is not good, especially in high voltage gain applications.

As for diode-assisted boost converter, the voltage stress of the switching devices is reduced to the intermediate capacitor voltage $\left(V_{C}\right)$, which is almost half of the output voltage when the voltage gain is high. Therefore, the switching loss can be reduced to a large extent while the conduction loss difference is not distinct since the on-state currents of the switching devices are almost the same under high voltage gain applications when compared with conventional boost converter. Furthermore, the advantage in terms of switching losses becomes more obvious with an increase in the switching frequency.

In order to quantify the improvement, the main circuit efficiency of the two boost converters is measured under different voltage gains by adjusting the input voltage $\left(V_{i n}\right)$ and regulating the output power $\left(V_{o}\right)$ with the change of load resistance. Figs. 8 and 9 show the corresponding efficiency comparison results respectively. Evidently, diode-assisted boost converter demonstrates higher efficiency than that of conventional converter under wide range voltage regulation, especially in high step-up applications. As illustrated in Fig. 8, when both converters operate under the relatively low voltage gain, the conventional boost converter exhibits better performance due to the small number of switching devices. However, in high step-up applications, the large input current and high output voltage increase the switching loss and conduction loss of the power devices and quickly lower the efficiency. Under the same conditions, for diode-assisted boost converter, the relatively small voltage stress of the power devices illustrated in Fig. 3(a) helps to reduce the switching loss to a large extent. Thus, the discrepancy in the efficiency between both converters becomes obvious with the decreasing input voltage. As illustrated in Fig. 9, diode-assisted boost converter shows higher efficiency than that of conventional boost converter in high step-up applications under the full range of output power. Therefore, diode-assisted converter provides a potential both high efficiency and high power-density design approach in renewable energy applications. Furthermore, the new topology reduces $(S D P)_{S U M}$, which means less silicon device requirements for the power converter. 


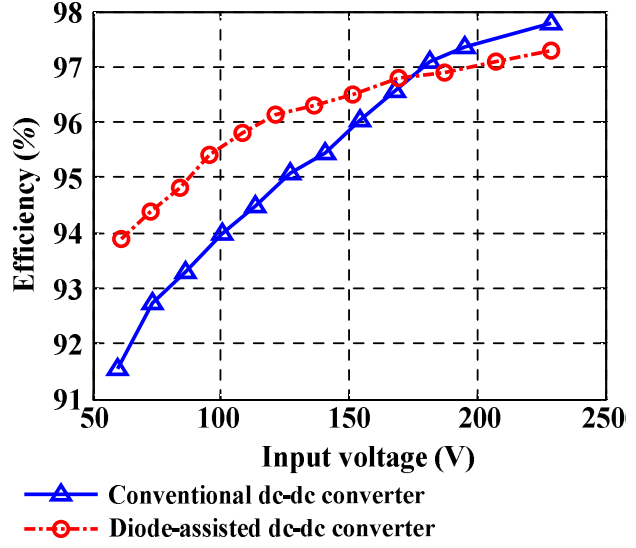

Fig. 8. Main circuit efficiency of two boost converters with the changing of input voltage $\left(V_{\text {in }}=60 \mathrm{~V} \sim 250 \mathrm{~V}, V_{o}=540 \mathrm{~V}, R=250 \Omega\right.$, $\left.f_{s}=10 \mathrm{kHz}\right)$

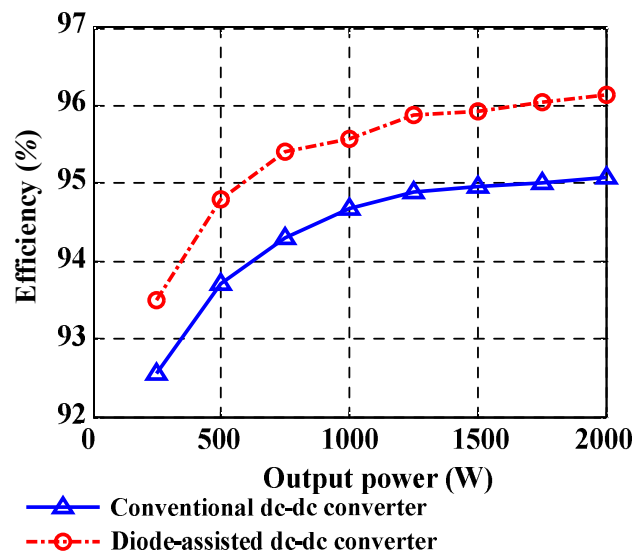

Fig. 9. Main circuit efficiency of two boost converters under different output power $\left(V_{\text {in }}=120 \mathrm{~V}, V_{o}=540 \mathrm{~V}, P_{o}=250 \mathrm{~W} \sim 2 \mathrm{~kW}\right.$, $\left.f_{s}=10 \mathrm{kHz}\right)$.

\section{CONCLUSIONS}

In this paper, three sets of dc-dc converters were compared comprehensively. The requirements for the switching devices and passive components were discussed in detail and shown as curves. Mathematical analysis results showed that diodeassisted dc-dc converters have many advantages such as low requirements for both the silicon devices and passive components, as well as high efficiency in high step-up/step-down power conversions. In general, conventional dc-dc converters are very competitive in the relatively low boost/buck ratio range. Numerical experiment results are included to verify the theoretic analysis. From the comparison results, it can be seen that diode-assisted dc-dc converters are very promising in the renewable energy applications where high step-up/step-down capability is regarded as a very important characteristic.

\section{APPENDIX}

A. Switching Device Voltage Stress, Current Stress and Power Rating Derivation:

1) Conventional Boost Converter: For conventional boost converter, the voltage stress of each switching device is the maximum output voltage.

$$
V_{S_{-} S}=V_{S_{-} D}=G \cdot V_{\text {in }}
$$

The on-state current of $S$ and $D$ is the inductor current in the steady state. The average current stress of $S$ and $D$ is:

$$
\begin{gathered}
I_{S_{-} S}=k_{\text {on }} \cdot i_{L}=\frac{G-1}{G} \cdot I_{\text {in }} \\
I_{S_{-} D}=\left(1-k_{o n}\right) \cdot i_{L}=\frac{1}{G} \cdot I_{\text {in }} .
\end{gathered}
$$

The switching device power rating $(S D P)$ is defined as the product of the voltage stress and current stress. This is introduced to indicate the silicon device requirements. The total switching device power rating of conventional boost converters can be expressed as:

$$
(S D P)_{\text {sum }}=V_{S_{-} S} \cdot I_{S_{-} S}+V_{S_{-} D} \cdot I_{S_{-} D}=G \cdot P_{i n} .
$$

2) Diode-assisted Boost Converter: For diode-assisted boost converter, there are two operation modes according to the switching state of $S$. Fig. 10 shows the corresponding equivalent circuits.

As is illustrated in Fig. 10, the blocking voltage of each switching device is the intermediate capacitor voltage.

$$
V_{S}=V_{c 1}=\frac{V_{i}}{1-D}=\frac{G+1}{2} V_{\text {in }} .
$$

The on-state current of $S$, shown in Fig. 10 (a), is the sum of the current across $L$ and $L_{f}$. The average current values of $L$ and $L_{f}$ are equal to the input and output currents, respectively.

$$
i_{S}=i_{L}+i_{L_{f}}=I_{\text {in }}+I_{o}=\frac{G+1}{G} \cdot I_{i n}
$$

The on-state current of $D_{1}$ or $D_{2}$, shown in Fig. 10 (b), meets:

$$
\left\{\begin{array}{l}
i_{L}=i_{C}+i_{D} \\
i_{D}=i_{C}+i_{L_{f}}
\end{array}\right.
$$

Solving the above equation, $i_{D}$ is:

$$
i_{D}=\frac{i_{L}+i_{L_{f}}}{2}=\frac{G+1}{2 G} \cdot I_{i n} .
$$

The average current stresses of $S$ and $D$ are:

$$
\begin{gathered}
I_{S_{-} S}=k_{o n} \cdot i_{S}=\frac{G-1}{G} \cdot I_{\text {in }} \\
I_{S_{-} D}=\left(1-k_{o n}\right) \cdot i_{D}=\frac{1}{G} \cdot I_{\text {in }}
\end{gathered}
$$

The total switching device power rating of diode-assisted boost converter can be expressed as:

$$
(S D P)_{\text {sum }}=V_{S_{-} S} \cdot I_{S_{-} S}+2 \cdot V_{S_{-} D} \cdot I_{S_{-} D}=\frac{(G+1)^{2}}{2 G} \cdot P_{i n}
$$




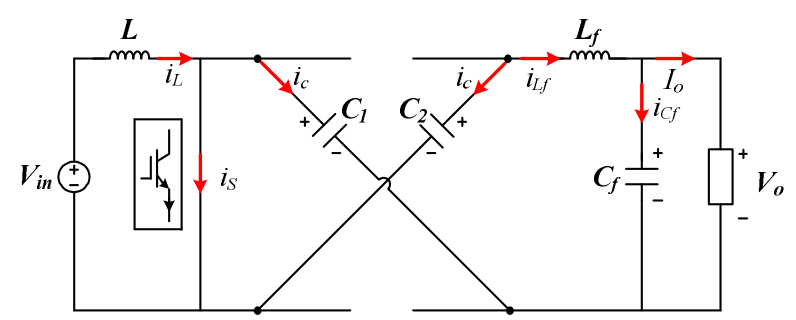

(a) During $S=\mathrm{ON}$ interval.

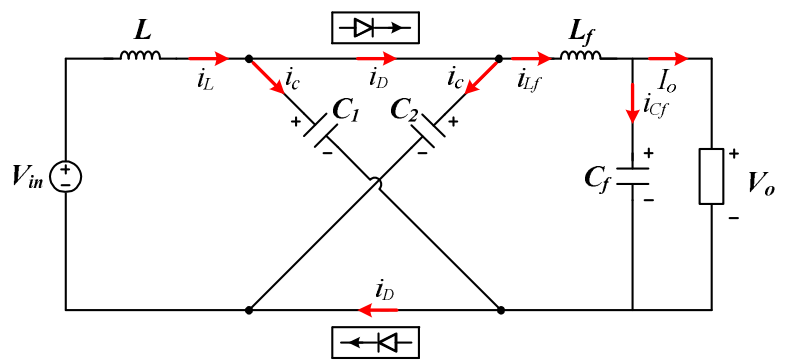

(c) During $S=\mathrm{OFF}$ inerval.

Fig. 10. Equivalent circuit of diode-assisted boost converter.

\section{B. Passive Components Requirements Derivation}

1) Conventional Boost Converter: For conventional boost converter, the inductor current increases during $S=\mathrm{ON}$ interval and the corresponding charging voltage is $V_{i n}$. Thus, the current ripple meets:

$$
\Delta I_{L}=\frac{k_{o n} T_{s}}{L} \cdot V_{\text {in }}=\frac{G-1}{G} \cdot \frac{V_{\text {in }}}{L \cdot f_{s}} .
$$

By substituting (29) and (10) into (12), $K_{L}$ for conventional boost converter is obtained as:

$$
K_{L(\text { Boost })}=\frac{G-1}{G} .
$$

As for the output capacitor, the charging current during $S=\mathrm{OFF}$ interval and the discharging current during $S=\mathrm{ON}$ interval are:

$$
\begin{gathered}
i_{C_{-} O N}=-I_{o}=-\frac{1}{G} \cdot I_{i n} \\
i_{C_{-} \text {OFF }}=I_{\text {in }}-I_{o}=\frac{G-1}{G} \cdot I_{\text {in }} .
\end{gathered}
$$

The voltage ripples of the output capacitor in the steady state is:

$$
\Delta V_{C}=\left(1-k_{o n}\right) \cdot \frac{i_{C \_O F F}}{C \cdot f_{s}}=\frac{G-1}{G^{2}} \cdot \frac{I_{\text {in }}}{C \cdot f_{s}} .
$$

In one switching time period, the RMS value of the capacitor current ripple meets:

$$
I_{C_{-} r m s}^{2}=\frac{1}{T}\left(\int_{o}^{k_{o n} \cdot T_{s}} i_{C_{-} O N}^{2} d t+\int_{k_{o n} \cdot T}^{T_{s}} i_{C_{-} O F F}^{2} d t\right)=\frac{G-1}{G^{2}} \cdot I_{i n}^{2} .
$$

By substituting (33), (34) and (11) into (13) and (14), $K_{C}$ and $K_{I C}$ for conventional boost converter are obtained as:

$$
\begin{aligned}
& K_{C(\text { Boost })}=\frac{G-1}{G^{3}} \\
& K_{I C(\text { Boost })}=\frac{G-1}{G^{2}} .
\end{aligned}
$$

2) Diode-assisted Boost Converter: For diode-assisted boost converter, the current of $L$ and $L_{f}$ increase during $S=\mathrm{ON}$ interval. The charging voltage of $L$ and $L_{f}$ are $V_{i n}$ and $V_{i}-V_{o}$, respectively. Thus, the current ripples of $L$ and $L_{f}$ meet:

$$
\begin{gathered}
\Delta I_{L}=\frac{k_{o n} T_{s}}{L} \cdot V_{\text {in }}=\frac{G-1}{G+1} \cdot \frac{V_{\text {in }}}{L \cdot f_{s}} \\
\Delta I_{L_{f}}=\frac{k_{o n} T_{s}}{L_{f}} \cdot\left(2 V_{C}-V_{o}\right)=\frac{G-1}{G+1} \cdot \frac{V_{\text {in }}}{L_{f} \cdot f_{s}} .
\end{gathered}
$$

By substituting (37) and (10) into (12), $K_{L}$ for diode-assisted boost converter is obtained as:

$$
K_{L\left(D_{-} \text {Boost }\right)}=\frac{G-1}{G+1} .
$$

As is illustrated in Fig.10, the current across the intermediate capacitor during $S=\mathrm{ON}$ interval and $S=\mathrm{OFF}$ interval are as follows:

$$
\begin{gathered}
i_{C_{-} O N}=-i_{L_{f}}=-\frac{1}{G} \cdot I_{i n} \\
i_{C_{-} \text {OFF }}=\frac{i_{L}-i_{L_{f}}}{2}=\frac{G-1}{2 G} \cdot I_{\text {in }} .
\end{gathered}
$$

The voltage ripple of the intermediate capacitor in the steady state is:

$$
\Delta V_{C}=\left(1-k_{\text {on }}\right) \cdot \frac{i_{C_{-} \text {OFF }}}{C \cdot f_{s}}=\frac{G-1}{G \cdot(G+1)} \cdot \frac{I_{\text {in }}}{C \cdot f_{s}} .
$$

In one switching time period, the RMS value of the capacitor current ripple meets:

$$
I_{C_{-} r m s}^{2}=\frac{1}{T}\left(\int_{o}^{k_{o n} \cdot T_{s}} i_{C_{-} O N}^{2} d t+\int_{k_{o n} \cdot T}^{T_{s}} i_{C_{-} O F F}^{2} d t\right)=\frac{G-1}{2 G^{2}} \cdot I_{i n}^{2} .
$$

By substituting (42), (43) and (11) into (13) and (14), $K_{C}$ and $K_{I C}$ for diode-assisted boost converter are obtained as:

$$
\begin{aligned}
K_{C\left(D_{-} \text {Boost }\right)} & =\frac{2(G-1)}{G(G+1)^{2}} \\
K_{I C\left(D_{-} \text {Boost }\right)} & =\frac{G-1}{2 G^{2}}
\end{aligned}
$$

As for the output capacitor $C_{f}$, the voltage and current ripple derivation approach is similar to that of the typical $L C$ filter design in conventional buck dc-dc converter [10]. Fig. 11 shows the typical waveforms of the inductor current $\left(i_{L f}\right)$ and capacitor voltage $\left(v_{C f}\right)$ for the output $L C$ filter in diode-assisted boost converter.

For the capacitor in conventional buck converter, the te rminal voltage is the output voltage $\left(V_{C}=V_{o}\right)$. As is illustra ted in Fig. 11, the charge stored in $C_{f}$ in one switching ti me period $\left(T_{s}\right)$ is $\Delta Q_{C f}$, which can be obtained as: 


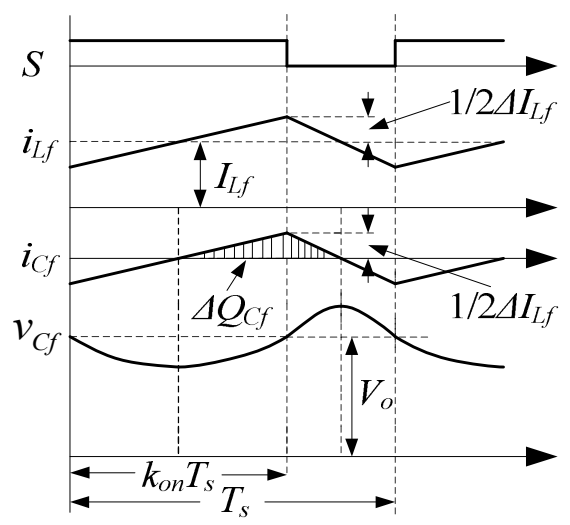

Fig. 11. Typical waveforms of $i_{L f}$ and $v_{C f}$ for the output $L C$ filter of diode-assisted boost converter.

$$
\Delta Q_{C_{f}}=\frac{1}{2} \frac{\Delta I_{L_{f}}}{2} \frac{T_{s}}{2}=\frac{\Delta I_{L_{f}}}{8 f_{s}}
$$

Then, the corresponding voltage ripple is:

$$
\Delta V_{C_{f}}=\frac{\Delta Q_{C_{f}}}{C_{f}}=\frac{\Delta I_{L_{f}}}{8 C_{f} f_{s}} .
$$

According to the principles of plane geometry, the $R M S$ current ripple is:

$$
I_{C_{f_{-} r} r m s}^{2}=\frac{1}{T_{s}}\left(\int_{o}^{k_{o n} \cdot T_{s}} i_{C_{f_{-} O N}}^{2} d t+\int_{k_{o n} \cdot T_{s}}^{T_{s}} i_{C_{f_{-}} O F F}^{2} d t\right)=\frac{\Delta I_{L_{f}}^{2}}{12}
$$

\section{ACKNOWLEDGMENT}

This work was supported in part by the National Basic Research Program (973 Program) of China under Project 2009CB219705 and in part by the State Key Laboratory of Electrical Insulation and Power Equipment under the Project EIPE09109.

\section{REFERENCES}

[1] J. Momoh, Renewable Energy and Storage, Wiley, New York, 2012.

[2] M. Nehrir and C. Wang, Modeling and Control of Fuel Cells: Distributed Generation Applications, Wiley, New York, 2009.

[3] X. Yu, M. R. Starke, and L. M. Tolbert, "Fuel cell power conditioning for electric power applications: a summary," IEEE Trans. Ind. Appl., Vol.1, No.5, pp. 643-656, Sep. 2007.

[4] S. Nguyen Van, W. Choi, and D.-W. Kim, "Non-isolated boost charger for the Li-Ion batteries suitable for fuel cell powered laptop computers," Journal of Power Electronics, Vol. 13, No. 1, pp. 31-39, Jan. 2013.

[5] W. Li and X. He, "Review of nonisolated high-step-up $\mathrm{dc} / \mathrm{dc}$ converters in photovoltaic grid-connected applications," IEEE Trans. Ind. Electron., Vol. 58, No. 4, pp. 1239-1250, Apr. 2011.

[6] A. B. Jidin, N. R. B. N. Idris, and A. H. B. M. Yatim, "A wide-speed high torque capability utilizing overmodulation strategy in DTC of induction machines with constant switching frequency controller," IEEE Trans. Power Electron., Vol. 27, No. 5, pp. 2566-2575, May. 2012.

[7] A. M. Howlader, N. Urasaki, and A. Y. Saber, "Optimal PAM control for a buck boost DC-DC converter with a wide-speed-range of operation for a PMSM," Journal of Power Electronics, Vol. 10, No. 5, pp. 477-484, Sep. 2010.

[8] K. Shu-Kong and D. D. C. Lu, "A high step-down transformerless single-stage single-switch AC/DC converter," IEEE Trans. Power Electron., Vol. 28, No.4 pp. 36-45, Apr. 2013.

[9] K. Yao, Y. Mao, X. Ming, and F. C. Lee, "Tappedinductor buck converter for high-step-down DC-DC conversion," IEEE Trans. Power Electron., Vol. 20, No.1 pp. 775-780, 2005.

[10] M. H. Rashid, Power electronics: circuits, devices, and applications, Prentice Hall, 2nd ed., New Jersey, 1988.

[11] H. Nomura, K. Fujiwara, and M. Yoshida, "A new DC-DC converter circuit with larger step-up/down ratio," PESC '06, pp. 1-7, Jun. 2006.

[12] E. H. Ismail, M. A. Al-Saffar, and A. J. Sabzali, "High conversion ratio DC-DC converters with reduced switch stress," IEEE Trans. Circuits Syst. I, Reg. Papers, Vol. 55, No. 7, pp. 2139-2151, Aug. 2008

[13] E. H. Ismail, M. A. AI-Saffar, A. J. Sabzali, and A. A. Fardoun, "A family of single-switch PWM converters with high voltage-boosting conversion ratio," IEEE Trans. Circuits Syst. I, Reg. Papers, Vol. 55, No. 4, pp. 1159-1171, May 2008.

[14] O. Abutbul, A. Gherlitz, and Y. Berkovich, "Step-up switching-mode converter with high voltage gain using a switched-capacitor circuit," IEEE Trans. Circuits Syst. I, Fundam. Theory Appl., Vol. 50, No. 8, pp. 1098-1102, Aug. 2003.

[15] B.-D. Min, J.-P. Lee, J.-H. Kim, T.-J. Kim, D.-W. Yoo, K.-R. Ryu, J.-J. Kim, and E.-H. Song, "A novel gridconnected PV PCS with new high efficiency converter," Journal of Power Electronics, Vol. 8, No. 4, pp. 309-316, Oct. 2008.

[16] Q. Zhao and F. C. Lee, "High-efficiency, high step-up DC-DC converters," IEEE Trans. Power Electron., Vol. 18, No.1, pp. 65-73, Jan. 2003.

[17] R. J. Wai, C. Y. Lin, and C. C. Chu, "High step-up DC-DC converter for fuel cell generation system," in Proc. IEEE IECON'04, pp. 57-62, 2004.

[18] Y. Tao and S. J. Park, "A novel ripple-reduced DC-DC converter," Journal of Power Electronics, Vol. 9, No. 3, pp. 396-402, May 2009.

[19] J.-H. Kim, D.-Y. Jung, S.-H. Park, and S.-W. Lee, "High efficiency soft-switching boost converter using a single switch," Journal of Power Electronics, Vol. 9, No. 6, pp. 929-939, Nov. 2009.

[20] F. Z. Peng, "Z-Source inverter," IEEE Trans. Ind. Appl., Vol. 39, No. 2, pp. 504-510, Mar. 2003

[21] F. Gao, P. C. Loh, R. Teodorescu, and F. Blaabjerg, "Diode-assisted buck-boost voltage-source inverters," IEEE Trans. Power Electron., Vol. 24, No. 9, pp. 2057-2064, Sep. 2009.

[22] Y. Zhang and J. Liu, "Improved pulse-width modulation of diode-assisted buck-boost voltage source inverter," IEEE Trans. Power Electron., Vol. 28, No. 8, pp. 3675-3699, Aug. 2013. 
[23] F. Gao, C. Liang, and P. C. Loh, "Buck-boost currentsource inverters with diode-inductor network," IEEE Trans. Ind. Appl., Vol. 45, No. 2, pp. 794-804, Apr. 2009.

[24] M. Shen, J. Wang, and F. Z. Peng, "Comparison of traditional inverters and Z-Source inverter for fuel cell vehicles," IEEE Trans. Power Electron., Vol. 22, No. 4, pp. 1453-1463, Jul. 2007.

[25] M. Mohr, W. T. Franke, and B. Wittig, "Converter systems for fuel cells in the medium power range - A comparative study," IEEE Trans. Ind. Electron., Vol. 57, No. 6, pp. 2024-2032, Jun. 2010.

[26] Y. Zhang, J. Liu, and C. Zhang, "Comparison of traditional two-stage buck-boost voltage source inverter and diode-assisted buck-boost voltage source inverter," in Proc. Appl. Power Electron. Conf. Expo., pp. 141-148, 2012.

[27] J. W. Kolar and S. D. Round, "Analytical calculation of the RMS current stress on the DC-link capacitor of voltage-PWM converter systems," IEE ProceedingsElectric Power Applications, pp. 535-543, 2006.

[28] A. M. Bazzi, P. T. Krein, and J. W. Kimball, "IGBT and diode loss estimation under hysteresis switching," IEEE Trans. Power Electron., Vol. 27, No. 3, pp. 1044-1048, Mar. 2012.

[29] F. Blaabjerg, J. Pedersen, and A. Elkjaer, "An extended model of power losses in hard-switched IGBT inverters," in Proc. 31st IAS Annu. Meeting, Conf. Record of IEEE Ind. Appl. Conf., pp. 3006-3012, 1996.

[30] D. Graovac and M. Purschel, "IGBT power losses calculation using the data-sheet parameters," Infineon Neubiberg, Germany, Tech. Rep., Appl.Notes, pp. 3-6, Jul. 2006 .

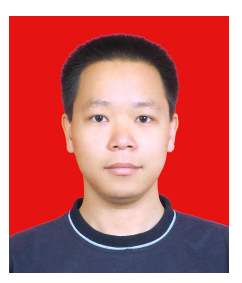

Yan Zhang received his B.S. and M.S. degrees in Electrical Engineering from Xi'an University of Technology (XAUT), Xi'an, China, in 2006 and 2009, respectively. He is currently pursuing his $\mathrm{Ph} . \mathrm{D}$. degree in the School of Electrical Engineering at Xi'an Jiaotong University (XJTU), Xi'an, China. His current research interests include modeling and control of power electronic systems, high efficiency and high power density power converters, and power-electronics applications in renewable energy and distributed generation.

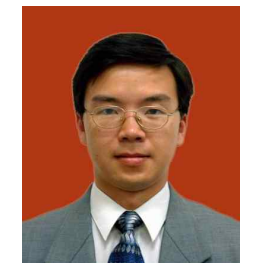

Jinjun Liu received his B.S. and Ph.D. degrees in Electrical Engineering from Xi'an Jiaotong University (XJTU), Xi'an, China, in 1992 and 1997, respectively. He then joined the School of Electrical Engineering at XJTU as a member of the teaching faculty. In 1998, he led the founding of the XJTU/Rockwell Automation Laboratory and served as the Lab Director. From 1999 until early 2002, he was a Visiting Scholar in the Center for Power Electronics Systems at Virginia Polytechnic Institute and State University, Blacksburg, VA, USA. He then returned to XJTU and in late 2002 was promoted to a Full Professor and the head of the Power Electronics and Renewable Energy Center at XJTU. From 2005 until early 2010, he served as the Associate Dean for the School of Electrical Engineering at XJTU. He is presently serving as the Dean of Undergraduate Education at XJTU. He coauthored 3 books, published over 100 technical papers, holds 13 patents, and has received several national, provincial or ministerial awards for scientific or career achievements. In 2006, he received the Delta Scholar Award. His current research interests include power quality control, renewable energy generation, utility applications of power electronics, and modeling and control of power electronic systems. Dr. Liu is an AdCom Member of the IEEE Power Electronics Society and serves as Region 10 Liaison. He also serves as an Associate Editor for the IEEE TRANSACTIONS ON POWER ELECTRONICS. $\mathrm{He}$ is an AdCom Member and the Chair of Student Activities Committee for IEEE Xi'an Section. He is on Board of China Electrotechnical Society (CES) and serving as a Vice President for CES Power Electronics Society. He is also on the Executive Board and serving as a Vice President for the China Power Supply Society.

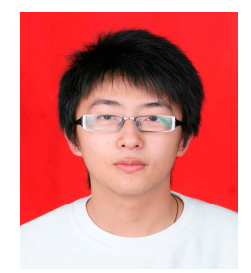

Xiaolong Ma received his B.S. degree in Electrical Engineering from Xi'an Jiaotong University (XJTU), Xi'an, China, in 2013, where he is currently pursuing his M.S. degree in the School of Electrical Engineering. His current research interests include modeling and control of power converters, single-phase renewable energy. PFC and power-electronics applications in

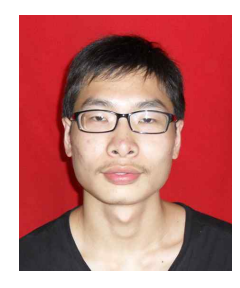

Junjie Feng is currently pursuing his B.S. degree in Electrical Engineering at Xi'an Jiaotong University (XJTU), Xi'an, China. In 2013, he joined the Power Electronics and Renewable Energy Research Centre at XJTU. His current research interests include powerelectronics applications in renewable energy and embedded system designs. 